\title{
INCOSE Systems Engineering Handbook v3.2: Improving the Process for SE Practitioners
}

\section{INCOSE 2010}

R. Douglas Hamelin

David C. Walden

Michael E. Krueger

July 2010

The INL is a

U.S. Department of Energy

National Laboratory

operated by

Battelle Energy Alliance

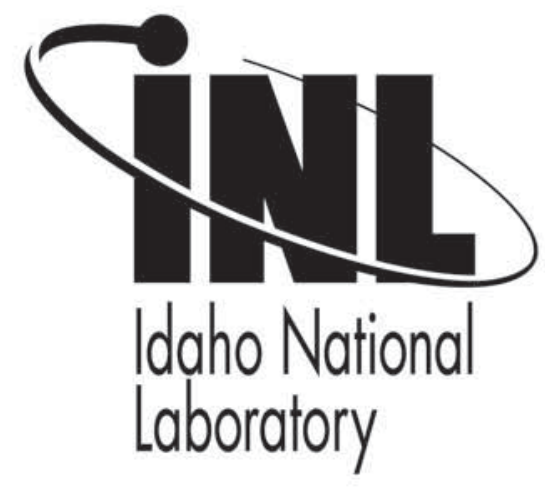

This is a preprint of a paper intended for publication in a journal or proceedings. Since changes may be made before publication, this preprint should not be cited or reproduced without permission of the author. This document was prepared as an account of work sponsored by an agency of the United States Government. Neither the United States Government nor any agency thereof, or any of their employees, makes any warranty, expressed or implied, or assumes any legal liability or responsibility for any third party's use, or the results of such use, of any information, apparatus, product or process disclosed in this report, or represents that its use by such third party would not infringe privately owned rights. The views expressed in this paper are not necessarily those of the United States Government or the sponsoring agency. 


\title{
INCOSE Systems Engineering Handbook v3.2: Improving the Process for SE Practitioners
}

\author{
R. Douglas Hamelin \\ Idaho National Laboratory \\ 2525 N. Fremont Ave. \\ P.O. Box 1625 \\ Idaho Falls, ID 83415-3780 \\ (208) 526-2337 \\ douglas.hamelin@inl.gov
}

\author{
David D. Walden \\ Sysnovation LLC \\ 13741 Johnson Memorial Dr. \\ Shakopee, MN 55379 \\ (952) 807-1388 \\ dave@sysnovation.com
}

\author{
Michael E. Krueger \\ ASE Consulting LLC \\ 899 Mango St. \\ Brea, CA 92821 \\ (714) 674-0406
}

michael.krueger@ase-consult.com

Copyright $(\odot 2010$ by Battelle Energy Alliance, LLC. Published and used by INCOSE with permission.

\begin{abstract}
The INCOSE Systems Engineering Handbook is the official INCOSE reference document for understanding systems engineering (SE) methods and conducting SE activities. Over the years, the Handbook has evolved to accommodate advances in the SE discipline and now serves as the basis for the Certified Systems Engineering Professional (CSEP) exam. Due to its evolution, the Handbook had become somewhat disjointed in its treatment and presentation of SE topics and was not aligned with the latest version of International Organization for Standardization (ISO)/International Electrotechnical Commission (IEC) 15288:2008, Systems and Software Engineering. As a result, numerous inconsistencies were identified that could confuse practitioners and directly impact the probability of success in passing the CSEP exam. Further, INCOSE leadership had previously submitted v3.1 of the Handbook to ISO/IEC for consideration as a Technical Report, but was told that the Handbook would have to be updated to conform with the terminology and structure of new ISO/IEC15288:2008, Systems and software engineering, prior to being considered.

The revised INCOSE Systems Engineering Handbook v3.2 aligns with the structure and principles of ISO/IEC 15288:2008 and presents the generic SE life-cycle process steps in their entirety, without duplication or redundancy, in a single location within the text. As such, the revised Handbook v3.2 serves as a comprehensive instructional and reference manual for effectively understanding SE processes and conducting SE and better serves certification candidates preparing for the CSEP exam.
\end{abstract}

\section{Background}

The INCOSE Systems Engineering Handbook, currently in its third major revision, is the official INCOSE reference document for understanding systems engineering (SE) methods and conducting SE activities. Over the years, the Handbook has evolved to accommodate advances in the SE discipline and now serves as the basis for the Certified Systems Engineering Professionals (CSEP) exam. Due to its evolution, the Handbook had become somewhat disjointed in its treatment and presentation of SE topics and was not aligned with the latest version of International Organization for Standardization (ISO)/International Electrotechnical 
Commission (IEC) 15288:2008, Systems and Software Engineering. As a result, numerous inconsistencies were identified that could confuse practitioners and directly impact the probability of success in passing the CSEP exam.

The 35-member Systems Engineering organization at the Idaho National Laboratory (INL) has over 750 years collective experience providing systems-based products and services to a broad range of government and private industry customers. Nine of those systems engineers are CSEP certified, one recently received Expert Systems Engineering Professional (ESEP) recognition, and an additional 15 are preparing to submit applications and take the CSEP exam. INL systems engineers identified numerous inconsistencies with the content and general structure of the Handbook v3.1 noting specifically that the organization of information required users to consult three or more separate locations within the text to fully understand a single process topic. Two of the INL CSEP recipients also noted that the structure and inconsistencies of Handbook v3.1 did not appear to adequately reflect the CSEP exam nor sufficiently prepare a CSEP candidate to navigate exam questions. Other CSEP candidates noted similar frustrations and identified the structure and inconsistencies of the handbook as a primary factor in their unsuccessful attempts to pass the exam. As a result, many of those currently preparing CSEP applications have questioned the value of CSEP certification.

The INL organization was aware of INCOSE's plans to issue a new Handbook, v4, in the 2012 timeframe, but felt that interim improvements could and should be made to address immediate concerns. As such, the INL SE Department formally proposed to review Handbook v3.1 in greater detail and assist INCOSE in correcting identified inconsistencies and improving the overall structure in a manner that would give current and future CSEP candidates a stronger probability of success. That proposal was accepted by the INCOSE Board of Directors in May 2009.

INCOSE leadership had also previously submitted the INCOSE SE Handbook v3.1 to the ISO/IEC for consideration as an ISO/IEC Technical Report supporting ISO/IEC 15288:2002, Systems Engineering - System Life-cycle Processes. In response, they were informed that the systems engineering standard had been recently updated to a new ISO/IEC 15288:2008, Systems and software engineering - System life-cycle processes, which combines common elements of the former systems engineering (15288:2002) and software engineering (12207:1995 and amendments) standards. For the Handbook to be considered as a Technical Report, INCOSE would have to update the text to conform to the terminology and structure of the new standard.

In light of the INL proposal and the ISO/IEC response, a team consisting of Michael Krueger (CSEP, ASE Consulting LLC), Dave Walden (CSEP, Sysnovation, LLC), and Douglas Hamelin (INL) was assembled to revise the Handbook. The members of revision team are the authors of this paper.

\section{Objectives}

The primary objectives of the INCOSE Systems Engineering Handbook v3.2 update were as follows:

1. Bring the text into alignment with ISO/IEC 15288:2008, System and software engineering - System life-cycle processes

2. Resolve technical inconsistencies in v3.1

3. Consolidate related process information throughout the text to remove the multiple and disjointed treatment of topics 
4. Minimize the impact to the Certified Systems Engineering Professional (CSEP) exam.

The team felt it was critical that the content and form of existing text be preserved to the extent possible to minimize impacts to the current CSEP exam. As such, the majority of inconsistency resolution and consolidation efforts focused more on format, placement of information, and deletion of redundant text than on technical revision.

\section{Alignment with ISO/IEC15288:2008}

As stated above, the ISO/IEC Software Engineering (12207:1995 and amendments) and Systems Engineering (15288:2002) standards were updated and integrated to resolve differences in terminology, process sets, process structures, levels of prescription, and intended audiences. The resulting ISO/IEC15288:2008, System and software engineering - System life-cycle processes, achieved that objective by providing a single standard with common vocabulary; a generic, integrated process; a single structure; and jointly planned levels of prescription applicable to a wide range of audiences, domains, and applications [Moore and Roedler, 2008]. The effort, undertaken by members of the ISO/IEC Joint Technical Committee for Information Technology (JTC1)/Subcommittee for Software and Systems Engineering (SC7), involved a detailed review and analysis of all related standards and guidance documents both within ISO/IEC and from other organizations. In all, 24 separate standards, ranging in topic from general terminology to quality, maintenance, and risk management, were evaluated and considered for inclusion in the new standards. Standard 15288:2002 was then addressed in detail, realigned, and expanded as the life-cycle process basis for the combined standard. This resulted in renaming and combining several process steps and inclusion of a new Measurement Process from ISO/IEC 15939, Software engineering - Software measurement process. Standard 12207:1995 was then considered and any software-related activities not already addressed by the realignment were binned into their respective life-cycle process step. Figures 1 and 2 show the transition from the 15288:2002 structure to that of 15288:2008 [see Moore and Roedler, 2008].

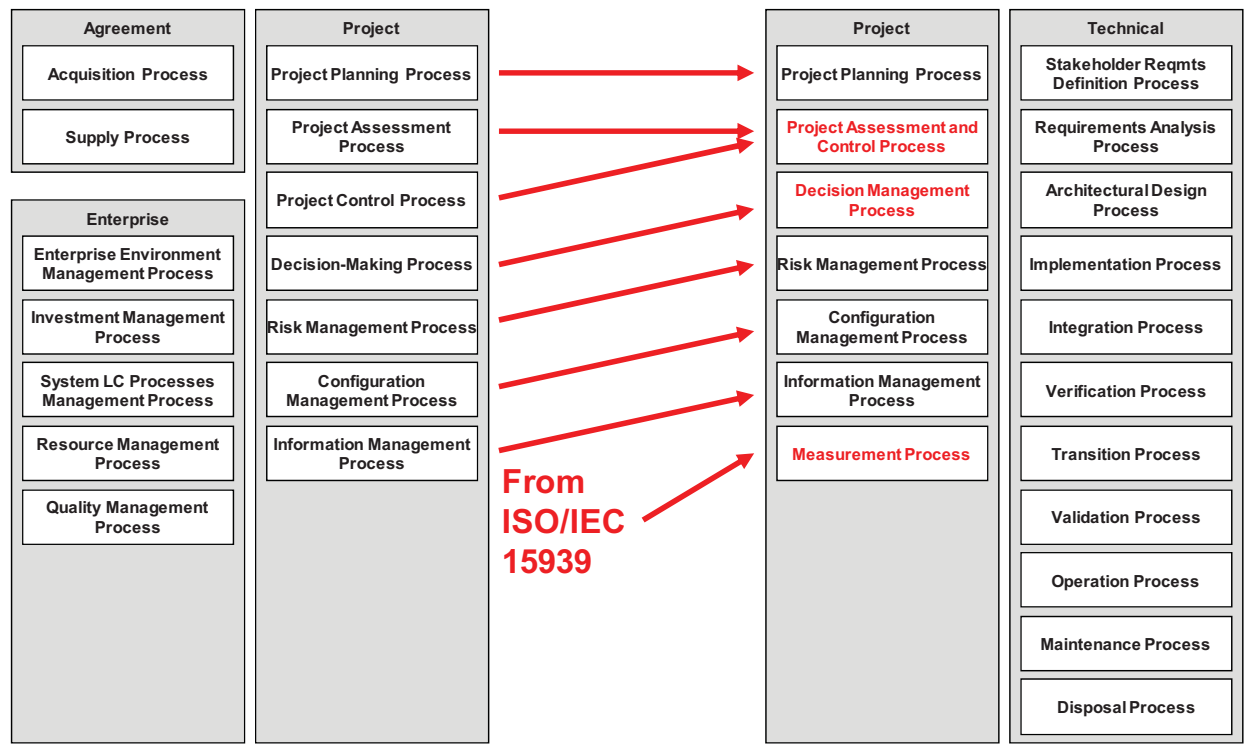

Figure 1. 15288:2008 Project Processes 


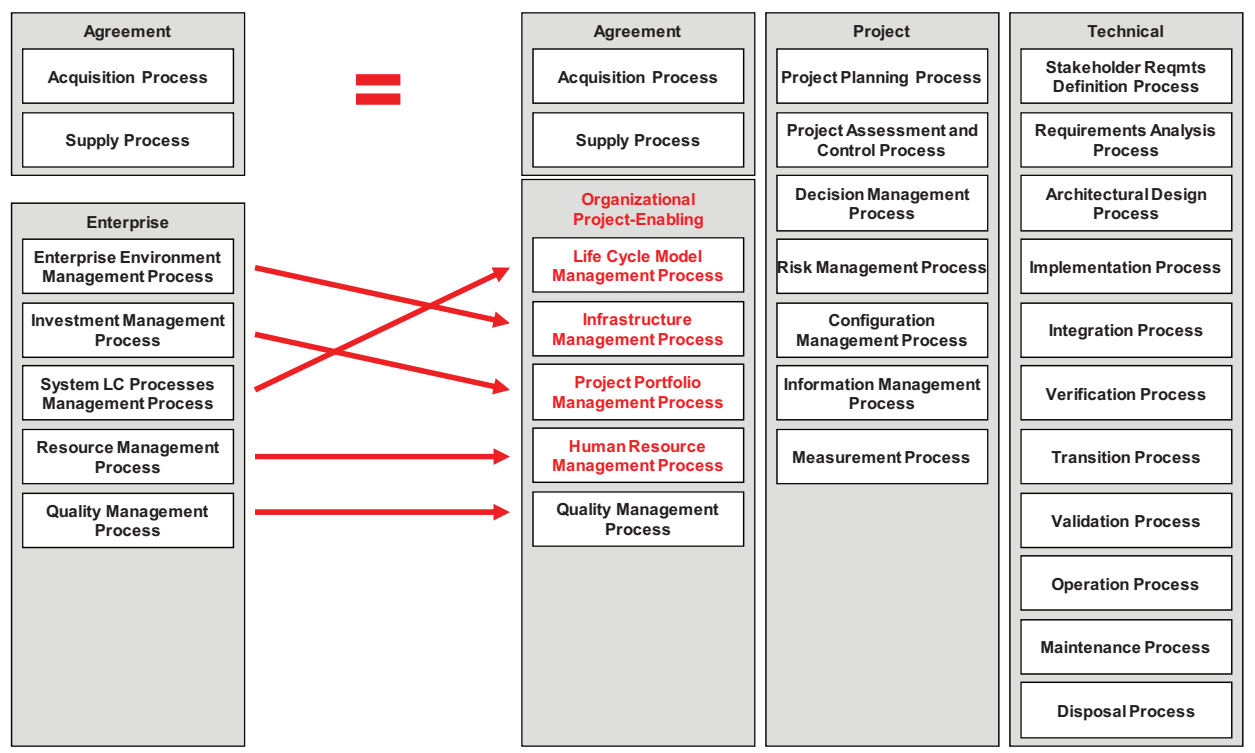

Figure 2. 15288:2008 Acquisition and Organizational Processes

Three key impacts resulted from this realign related to the structure of the revised INCOSE SE Handbook. The first is the organization of life-cycle process steps into four groupings rather than three, as was the case with Handbook v3.1. The second is the discontinuation of "enterprise" in favor of "organization/organizational" as a process term. Third, ISO/IEC 15288:2002 contained several references and comparisons to the general flow of competing life-cycle processes and provided a basis for the overview discussions contained in Chapter 3 of the Handbook. These references and associated illustrations no longer appear in 15288:2008, requiring that the revised Handbook v3.2 look to other sources as a basis, primarily ISO/IEC TR19760, Systems engineering - A guide for the application of ISO/IEC 15288 (System life cycle processes).

Considering the impacts posed by the new standard, the Handbook revision team reorganized Handbook v3.1 Chapters $4-6$ into v3.2 Chapters $4-7$ by moving the Enterprise Environment and related management process information from Chapter 6 to a new Chapter 7. Chapter 6 was thereby reduced to address only the two Agreement processes: Acquisition and Supply. The new Chapter 7, entitled Organizational Project-Enabling Processes, contains the most significant changes in that ISO/IEC 15288:2008 renames several of the subprocesses to highlight a stronger focus on organizations and projects (as opposed to enterprise) and, thus, necessitated a significant regrouping of the information contained in each of the subsections. Chapters 4 and 5 remain in much the same order as in v3.1, except for the addition of two new subsections: 4.12, Cross-Cutting Technical Methods, and 5.7, Measurement Process. These sections, along with other sections discussed below, were added to keep pace with the evolving nature of SE processes in general and to introduce emerging SE theories. A decision was also made to retain, to the extent possible, the original structure of v3.1 Chapters $4-6$ in the new Chapters 4- 7 to further emphasize the Handbook's alignment with the new ISO/IEC standard and to minimize the impact of these changes as they relate to CSEP exam questions. As such, each major section of Chapters $4-7$ still presents summary information specific to Purpose, Description, Inputs, Outputs, and Process Activities under a new Overview subheading. Additional content and other enhancements made to these chapters to further consolidate related process information are discussed in the next section of this paper. 
The discontinuation of the term "enterprise" and the renaming of all of the 15288:2002 Enterprise Processes to the 15288:2008 Organizational Project-Enabling Processes posed the most significant challenge to the editorial team. This change also impacted some of the CSEP exam questions, which directly used the 15288:2002 terms. Signification energy was spent by the team debating the cost and overall probability of CSEP exam success that such a change would impose. Ultimately, the desire for consistency with 15288:2008 took precedence and all instances of "enterprise" were changed in the text to read "organization" or "organizational," as appropriate. Given that decision and subsequent corresponding updates to the CSEP exam, CSEP candidates should be aware that any instances of "organization/organizational" appearing in the text may appear as "enterprise" on the exam until the CSEP exam questions are formally revised. A subsequent note was also added to the handbook. This should not impact the accuracy of the exam question or corresponding answer; rather, it is simply a matter of evolving terminology that readers should be aware of in their exam preparation.

\section{Resolution of Inconsistencies and Consolidation of Process Information}

In September 2008, the INL Systems Engineering organization participated in a 3-day course, presented by the Center for Systems Management (CSM), to begin preparing INL systems engineers for the INCOSE CSEP exam and to help them submit strong CSEP applications for approval by the INCOSE review committee. Following the initial training, course attendees conducted a series of in-house, self-taught brown-bag sessions to review and discuss the principles contained in Handbook v3.1. Each participant was assigned a Systems Engineering process "topic" (as opposed to a Handbook "chapter") and asked to prepare a 1-hour briefing as a basis for group discussion. The general plan to navigate the Handbook and provide a roadmap for topic discussion is shown in Table 1.

Three issues became quickly apparent. First, as shown in the second column of Table 1, very few "topics" were addressed in a single Handbook location. In v3.1, SE processes are introduced in general terms in Chapters $4-6$ using a structure and terminology consistent with ISO/IEC 15288:2002. Those same processes are then addressed in greater detail using a different organizational structure in Chapters 7 -9. Finally, the same processes are presented a third (and sometimes fourth) time in Appendices D - N to capture any techniques or practices not previously addressed in the chapter text. Subsequently, this disjointed structure required readers to flip back and forth between chapters and appendices to fully address a particular process step, most often resulting in a fragmented and incomplete understanding of the SE process in general.

Second, much of the chapter text in v3.1 is repeated almost verbatim in the appendices, while other portions of chapter text is inconsistent with similar text presented in the appendices, both in terminology and in process approach. In many cases, information from the chapter text was expanded and elaborated in the appendices, resulting in a disconnect as to the complete set of principles and practices that make up a process step.

Third, each section of v3.1 Chapters $4-6$ begins with a context diagram identifying the inputs, outputs, controls, and enablers of the process step being discussed. Each of those diagrams is then followed by additional details of the respective inputs and outputs that are often different and/or inconsistent with the diagrams. 
Table 1: INL CSEP Preparation Plan

\begin{tabular}{|c|c|c|}
\hline Topic & Handbook v3.1 Reference & Brownbag Dates \\
\hline Stakeholder Requirements & $4.2,7.2$, App I \& J & \multirow{2}{*}{ 9-Oct-08 } \\
\hline Requirements Analysis & 4.3, 7.2, App I \& J & \\
\hline Architecture & 4.4, 4.7, 8.2, 9.6, App E, K, L & \multirow{3}{*}{ 23-Oct-08 } \\
\hline Implementation & 4.5 & \\
\hline Integration & 4.6, App N & \\
\hline Verification & $4.7,8.10$ & \multirow{3}{*}{ 6-Nov-08 } \\
\hline Transition & 4.8 & \\
\hline Validation & $4.9,8.9$ & \\
\hline Operations & 4.10 & \multirow{4}{*}{ 20-Nov-08 } \\
\hline Maintenance & 4.11 & \\
\hline Disposal & 4.12 & \\
\hline Project Processes \& Planning & $5.1-5.8,8.6$ & \\
\hline Enterprise and Agreement & $6.1-6.8$ & \multirow{4}{*}{ 4-Dec-08 } \\
\hline Decision Mgmt & $7.1,5.5$ & \\
\hline Risk and Opportunity & $5.6,7.3$ & \\
\hline Acquisition and Supply & $8.1,9.1$, App F & \\
\hline Systems Engineering Planning & App G.1-G.3 & \multirow{3}{*}{ 8-Jan-09 } \\
\hline Tailoring & $10.1-10.3$ & \\
\hline Integrated Product and Process & App H & \\
\hline SE Analysis "ilities" Part 9.1 & $9.2-9.5,9.7-9.9 \quad 178-187$ & \multirow{2}{*}{ 22-Jan-09 } \\
\hline Human Systems & App M & \\
\hline Architecture & App E, K, L & \multirow{2}{*}{$5-F e b-09$} \\
\hline Integration & App N & \\
\hline Configuration Mgmt & 5.7, 8.3, App G.4 & \multirow{3}{*}{ 19-Feb-09 } \\
\hline Information \& Investment Mgmt & $8.4 \& 8.5$ & \\
\hline Quality \& Resource Mgmt & $8.7,8.8$ & \\
\hline
\end{tabular}

With these issues in mind, the INL proposed a new outline (based on its CSEP preparation plan) that reorganized the Handbook by topic and consolidate related chapters and appendices into subsections of the chapter text. The proposed outline was accepted by the revision team and combined with additional considerations imposed by the ISO/IEC 15288:2008 update to form the basis for the detailed restructuring that resulted in v3.2. A decision was made early on to retain the original structure of v3.1 Chapters $4-6$ to emphasize the Handbook's alignment with the new ISO/IEC standard while at the same time pulling related information forward from the later chapters and appendices. Subsequently, each processes Chapter in v3.2 was divided into two key subsections: Overview and Elaboration. The Overview section retains the original chapter structure and presents updated context diagrams and summary Purpose, Description, Inputs, Outputs, and Process Activities details consistent with ISO/IEC 15288:2008. The Elaboration section combines the text from v3.1 Chapters $7-9$ and appendices to present new, consolidated descriptions of the principles introduced in the Overview. Subsequently, v3.1 Chapters $7-9$ no longer appear in the Handbook as previously structured and have been replaced in v3.2 with Chapter 7, Organizational Project-Enabling Processes; Chapter 8, Tailoring Processes (formerly Chapter 10); and Chapter 9, Specialty Engineering Activities (formerly Chapter 8, Systems Engineering Support Activities). Figure 3 shows one example of the reorganization of v3.1 chapters and appendices to form the new v3.2 structure. 


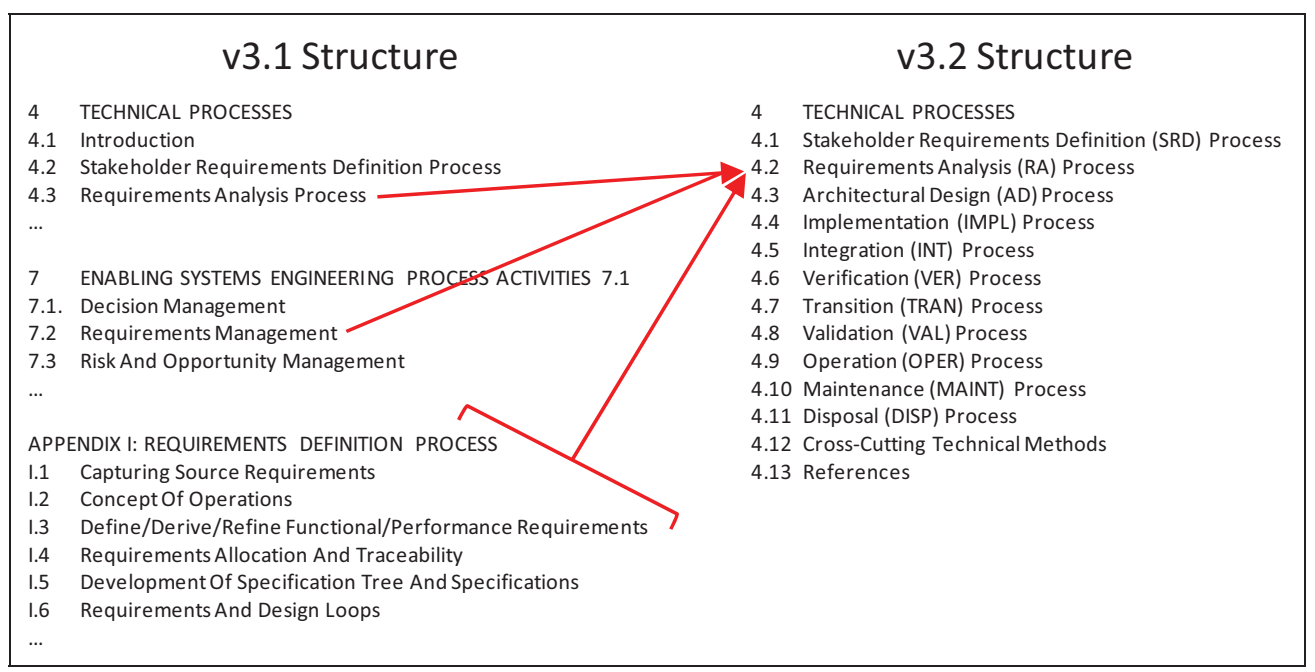

Figure 3. Sample of Handbook Restructuring

As mentioned above, much of the appendix text in v3.1 significantly expanded the list of key principles from the chapter text, particularly regarding the Inputs, Outputs, and Process Activities that in many cases were already inconsistent with the context diagrams. Hence, readers were often left to choose between as many as four distinctly different versions of what constituted a process step: the context diagram, the summary overview (in Chapters $4-6$ ), the enabling activities description (in Chapters 7 -9), and the detailed process description (in the Appendices).

In light of stated objectives, the revision team determined that combining the versions into a single, comprehensive set of details in the Overview section of each chapter and erring on the side of inclusion rather than exclusion posed the least impact to both ISO/IEC alignment and CSEP preparation. In short, keeping the larger, comprehensive set of expanded principles ensures that the Handbook remains consistent with ISO/IEC 15299:2008 while, at the same time, minimizes the need to alter the wording of CSEP exam questions to match the revised text. Further, the context diagrams were revised and updated to reflect the larger set of process principles upon which exam questions are based so that they can be used more effectively as a final review for the exam in addition to setting a broader context for the SE process steps to which they apply. The team used the CORE Systems Engineering tool from Vitech Corporation to create a model of the Handbook and to ensure consistency between all of the context diagram inputs and outputs.

The most significant effort, however, involved consolidating text from Chapters $7-9$ and the appendices to create new, comprehensive elaborations of the various SE processes. Redundant text was removed, paragraphs were reordered to improve flow and readability, inconsistent descriptions were compared and resolved to be consistent with ISO/IEC 15288:2008, and numerous illustrations were either added or revised to reflect evolutions in SE methodology and clarify otherwise vague or incomplete concepts. In a few cases, the absence of available elaboration information was identified and noted for inclusion in future revisions of the Handbook.

\section{Expansion and Addition of New Technical Information}

Another enhancement to v3.2 of the Handbook is the expansion and addition of select sections of the text to include recent advances in evolving SE principles and methodologies. New 
subsections were added to address the concepts of Lean Development (Section 3.3.3.3), Agile Development (Section 3.4.4), Measurement (Section 5.7), and other cross-cutting technical methods (Section 4.12), such as Modeling, Simulation, and Prototyping; Functions-Based Systems Engineering; and Object-Oriented Systems Engineering. Significant revisions were also made, in collaboration with subject matter experts, to text that addresses Modeling (Section 4.12.1), Systems Modeling Language, or SysML TM (Section 4.12.3), and Usability Analysis/Human Systems Integration (Section 9.12) to bring the information up-to-date with current theories and practices. Chapter 9 was expanded to introduce a variety of specialty engineering areas such that systems engineers can appreciate the significance of conducting specialty analyses, where appropriate, to enhance systems engineering outcomes. This includes the relabeling and restructuring of information from other v3.1 sections as Cost-Effectiveness Analysis, Interoperability Analysis, and Life-cycle Cost Analysis, and the addition of Value Engineering as a companion to typical functional and decision analysis processes.

The consolidation and addition of process information into the body of the text significantly reduced the number and content of the remaining appendices to address only those items intended to help the reader better navigate the text. These include a glossary of common SE terms, a complete list of acronyms used in the text, instruction on how to provide comments on Handbook v3.2, and acknowledgements for Handbook versions 3, 3.1, and 3.2. The inputs-outputs matrix presented in Appendix A was also revised to provide a more complete picture of the interdependencies of SE process steps. A new appendix has been added to map the location of SE life-cycle process steps presented in v3.2 with the corresponding location in five other industry-accepted standards:

- ISO/IEC 15288:2002

- ISO/IEC 15288:2008

- ISO/IEC 26702:2007/Institute of Electrical and Electronics Engineers (IEEE) 1220TM

- American National Standards Institute (ANSI) Electronics Industries Alliance (EIA)-632

- Capability Maturity Model Integration $\left(\mathrm{CMMI}^{\circledR}\right)$ for Development v1.2.

Figure 4 show a sample of the life-cycle process mapping between ISO IEC 15288:2002 and the revised Handbook v3.2.

\begin{tabular}{|c|c|c|}
\hline $\begin{array}{l}\text { ISO/IEC 15288:2002 System } \\
\text { Life Cycle Process }\end{array}$ & $\begin{array}{l}\text { INCOSE SE Handbook v3.2 } \\
\text { Section }\end{array}$ & Notes/Comments \\
\hline \multicolumn{3}{|l|}{ 6.1 Agreement Processes } \\
\hline 6.1.1 Acquisition Process & 6.1 Acquisition Process & \\
\hline 6.1.2 Supply Process & 6.2 Supply Process & \\
\hline \multicolumn{3}{|l|}{ 6.2 Enterprise Processes } \\
\hline $\begin{array}{l}\text { 6.2.1 Enterprise Environment } \\
\text { Management Process }\end{array}$ & $\begin{array}{l}7.1 \text { Life Cycle Model } \\
\text { Management Process }\end{array}$ & Policies \& procedures \\
\hline $\begin{array}{l}6.2 .2 \text { Investment } \\
\text { Management Process }\end{array}$ & $\begin{array}{l}\text { 7.3 Project Portfolio } \\
\text { Management Process }\end{array}$ & \\
\hline $\begin{array}{l}\text { 6.2.3 System Life Cycle } \\
\text { Process Mgmt Process }\end{array}$ & $\begin{array}{l}7.1 \text { Life Cycle Model } \\
\text { Management Process }\end{array}$ & $\begin{array}{l}\text { Methods \& tools } \\
\text { Enterprise measures }\end{array}$ \\
\hline
\end{tabular}

Figure 4. Sample Life-Cycle Process Mapping 
Finally, v3.2 now includes a comprehensive, topical index. This was added to aid readers in using the INCOSE SE Handbook as a reference text by giving them the ability to quickly locate select pieces of information by topic without having to read the entire text.

\section{Conclusion}

As a result of these efforts, the revised INCOSE Systems Engineering Handbook v3.2 aligns with the structure and principles of ISO/IEC 15288:2008. Further, SE life-cycle process steps are now presented in their entirety, without duplication or redundancy, in a single location within the text. As such, this revised Handbook serves as a comprehensive instructional and reference manual for effectively understanding SE processes and conducting SE work and better serves certification candidates preparing for the CSEP exam.

The INCOSE Systems Engineering Handbook v3.2 was formally accepted and approved by the INCOSE Technical Review Committee on January 25, 2010. The Handbook was also formally submitted for ballot consideration as an ISO/IEC Technical Report in March 2010, with comments and approval pending.

\section{References}

INCOSE. 2007. Systems Engineering Handbook - A Guide for System Life Cycle Processes and Activities, Version 3.1.

INCOSE. 2010. Systems Engineering Handbook - A Guide for System Life Cycle Processes and Activities, Version 3.2.

ISO/IEC 12207:2008 / IEEE Std 12207TM-2008, Systems and software engineering - Software life cycle processes, $2^{\text {nd }}$ Edition, Geneva: International Organization for Standardization, issued 1 February 2008.

ISO/IEC 15288:2008, Systems and software engineering - System life cycle processes, $2^{\text {nd }}$ Edition, Geneva: International Organization for Standardization, issued 1 February 2008.

ISO/IEC 15939:2007, Systems and software engineering - Measurement process, $2^{\text {nd }}$ Edition, Geneva: International Organization for Standardization, issued 1 October 2008.

ISO/IEC TR 19760:2003, Systems Engineering - A guide for the application of ISO/IEC 15288, Geneva: International Organization for Standardization, issued 15 November 2003.

Moore, James, and Garry Roedler. 2008. Summary of the Alignment of System and Software Life Cycle Process Standards. ISO/IEC JTC1/SC7.

\section{Disclaimer}

This manuscript has been authored by Battelle Energy Alliance, LLC under Contract No. DE-AC07-05ID14517 with the U.S. Department of Energy. The United States Government retains and the publisher, by accepting the article for publication, acknowledges that the United States Government retains a nonexclusive, paid-up, irrevocable, world-wide license to publish or reproduce the published form of this manuscript, or allow others to do so, for United States Government purposes.

\section{Biographies}

R. Douglas Hamelin (MA, English, Idaho State University) is a Systems Engineering Specialist and Technical Writer for the Idaho National Laboratory SE organization. Mr. Hamelin is trained in requirements management, contributes to a wide range of SE applications 
as a functional analyst and document specialist, and played a major role in developing a university training course entitled Applying Systems Engineering in the DOE Environment. Other contributions include document control, risk analysis, technology roadmapping, and decision support using a variety of software applications. Mr. Hamelin contributes on numerous DOE publications and most recently helped revise the INCOSE Systems Engineering Handbook v3.2.

David D. Walden, CSEP, is co-owner and principal consultant for Sysnovation, LLC, a Systems Engineering consulting and education firm based out of Shakopee, Minnesota, USA. He has served as an independent reviewer, major review (e.g., PDR, CDR) coordinator, Systems Engineering Subject Matter Expert (SME), and process consultant. He has created and taught numerous Systems Engineering courses and tutorials, including a distance learning on-line variant of a Systems Engineering Principles course. Previously, Mr. Walden was with General Dynamics Advanced Information Systems for 13 years and McDonnell Aircraft Company for 10 years. Mr. Walden is currently the Program Manger of the International Council on Systems Engineering's (INCOSE's) Certification Program and also serves as the INCOSE liaison to ISO/IEC JTC1/SC7 Working Groups 10, 20, and 22. He has an M.S. in Management of Technology (MOT) from the University of Minnesota, an M.S. in Electrical Engineering and an M.S. in Computer Science from Washington University in St. Louis, and a B.S. in Electrical Engineering from Valparaiso University in Indiana.

Michael E. Krueger of Advanced Systems Engineering Consulting (ASE Consulting LLC) is involved with Systems Engineering support and training to Caltrans and the Federal Highway Administration (FHWA). Mr. Krueger developed the Systems Engineering Guidebook for ITS, this seminal work is the first of its kind for the Transportation domain. Mr. Krueger was a co-editor for the INCOSE Systems Engineering Handbook version 3.1. Mr. Krueger is a Certified Systems Engineering Professional (CSEP) from the International Council on Systems Engineering (INCOSE) and serves on the Certification Advisory Group and Reviewer (CAG/CAR. Mr. Krueger is the Chair of the Intelligent Transportation Systems Special Interest Group and the past President of the Los Angeles Chapter of INCOSE. 